\title{
Investigation of serum isocitrate dehydrogenase, malate dehydrogenase and glutamate dehydrogenase activities with related oxidative stress markers in preeclampsia
}

\author{
Sahabettin Selek ${ }^{1}$, Ayse Zehra Gul ${ }^{1}$, Nil Atakul ${ }^{2}$, Sedat Meydan ${ }^{1}$, Alime Sarıkaya ${ }^{1}$, \\ Fatmanur Koktasoglu ${ }^{1}$, and Yildız Atamer $^{3}$ \\ ${ }^{1}$ Bezmialem Vakif University \\ ${ }^{2}$ Istanbul Teaching and Research Hospital \\ ${ }^{3}$ Beykent University
}

June 3, 2021

\begin{abstract}
Introduction: Preeclampsia, a high cause of fetomaternal morbidity-mortality, remains a significant burden affecting $8 \%$ of all pregnancies. Environmental conditions induce disease development leading to endothelial dysfunction in genetically predisposed women. Our aim is to discuss oxidative stress as a well-established contributing factor to disease progression with being the first study to show new evidence about serum dehydrogenase enzyme levels (isocitrate, malate, glutamate dehydrogenase) with oxidative markers (myeloperoxidase, total antioxidant-oxidant status, oxidative stress index). Methods: Serum parameters were analyzed with photometric method (Abbott ARCHITECT c8000). Results: Results showed that the enzyme levels and oxidative markers were significantly higher in patients, supporting the redox imbalance in preeclampsia. According to ROC analysis, malate dehydrogenase showed an outstanding diagnostic ability with the highest AUC value of 0.9 and the cut-off value of $51.2 \mathrm{IU} / \mathrm{L}$. Discriminant analysis including malate, isocitrate and glutamate dehydrogenase had predicted preeclampsia with an overall \%87.9 accuracy. Discussion: Considering the above results, we propose that the enzyme levels increase with oxidative stress functioning as antioxidant defense factors. The unique finding of the study is that the serum levels of malate, isocitrate and glutamate dehydrogenase can be used both separately and combined in the early prediction of preeclampsia. As a novel approach, we also offer combining serum isocitrate and glutamate dehydrogenase levels with ALT, AST tests to state liver functions more reliably in patients. Still, larger sample-sized studies investigating enzyme expression levels are required to confirm the recent findings and to reveal underlying mechanisms.
\end{abstract}

\section{Hosted file}

PE manuscript (ENZYMES)-nw.docx available at https://authorea.com/users/417666/articles/ 524681-investigation-of-serum-isocitrate-dehydrogenase-malate-dehydrogenase-andglutamate-dehydrogenase-activities-with-related-oxidative-stress-markers-in-preeclampsia

\section{Hosted file}

Tables (PE-enzymes).docx available at https://authorea.com/users/417666/articles/524681investigation-of-serum-isocitrate-dehydrogenase-malate-dehydrogenase-and-glutamatedehydrogenase-activities-with-related-oxidative-stress-markers-in-preeclampsia

\section{Hosted file}

Figures (PE-enzymes).docx available at https://authorea.com/users/417666/articles/524681investigation-of-serum-isocitrate-dehydrogenase-malate-dehydrogenase-and-glutamate- 
dehydrogenase-activities-with-related-oxidative-stress-markers-in-preeclampsia 